\title{
Genotype diversity of Trypanosoma cruzi in small rodents and Triatoma sanguisuga from a rural area in New Orleans, Louisiana
}

\author{
Claudia P Herrera*, Meredith H Licon, Catherine S Nation, Samuel B Jameson and Dawn M Wesson*
}

\begin{abstract}
Background: Chagas disease is an anthropozoonosis caused by the protozoan parasite Trypanosoma cruzi that represents a major public health problem in Latin America. Although the United States is defined as non-endemic for Chagas disease due to the rarity of human cases, the presence of $T$. cruzi has now been amply demonstrated as enzootic in different regions of the south of the country from Georgia to California. In southeastern Louisiana, a high T. cruzi infection rate has been demonstrated in Triatoma sanguisuga, the local vector in this area. However, little is known about the role of small mammals in the wild and peridomestic transmission cycles.

Methods: This study focused on the molecular identification and genotyping of T. cruzi in both small rodents and T. sanguisuga from a rural area of New Orleans, Louisiana. DNA extractions were prepared from rodent heart, liver, spleen and skeletal muscle tissues and from cultures established from vector feces. T. cruzi infection was determined by standard PCR using primers specific for the minicircle variable region of the kinetoplastid DNA (kDNA) and the highly repetitive genomic satellite DNA (satDNA). Genotyping of discrete typing units (DTUs) was performed by amplification of mini-exon and $18 \mathrm{~S}$ and 24Sa rRNA genes and subsequent sequence analysis.

Results: The DTUs Tcl, TcIV and, for the first time, Tcll, were identified in tissues of mice and rats naturally infected with T. cruzi captured in an area of New Orleans, close to the house where the first human case of Chagas disease was reported in Louisiana. The T. cruzi infection rate in 59 captured rodents was $76 \%$. The frequencies of the detected DTUs in such mammals were Tcl 82\%, Tcll 22\% and TcIV 9\%; 13\% of all infections contained more than one DTU.

Conclusions: Our results indicate a probable presence of a considerably greater diversity in T. cruzi DTUs circulating in the southeastern United States than previously reported. Understanding T. cruzi transmission dynamics in sylvatic and peridomestic cycles in mammals and insect vectors will be crucial to estimating the risk of local, vector-borne transmission of T. cruzi to humans in the United States.
\end{abstract}

Keywords: Trypanosoma cruzi, Triatoma sanguisuga, Genotyping, T. cruzi DTUs, Rodents, United States

\section{Background}

Chagas disease is an anthropozoonosis caused by the protozoan parasite Trypanosoma cruzi and represents a major public health problem in Latin America with a burden of disease five times higher than malaria as measured by DALYs [1]. Due to human migration from Chagas endemic countries, this disease, which has long been considered a disease of the poor in Latin America,

\footnotetext{
*Correspondence: cherrera@tulane.edu; wesson@tulane.edu Department of Tropical Medicine, Vector-Borne Infectious Disease Research Center, School of Public Health and Tropical Medicine, Tulane University, 1440 Canal Street, Rm. 1824, New Orleans, LA 70112, USA
}

has crossed borders and become a public health problem in non-endemic regions [2]. Although the United States (US) was initially defined as non-endemic for Chagas disease due to the rarity of human cases [3], T. cruzi has now been amply demonstrated as enzootic in different regions of the south of the country from Georgia to California $[1,4]$.

More than 130 triatomine insect species have been described throughout the Americas. Eleven of these species have been found naturally infected with the parasite in the US and are considered potential Chagas disease vectors. Of these species, Triatoma sanguisuga

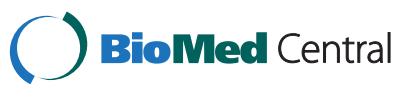

(C) 2015 Herrera et al.; licensee BioMed Central. This is an Open Access article distributed under the terms of the Creative Commons Attribution License (http://creativecommons.org/licenses/by/4.0), which permits unrestricted use, distribution, and reproduction in any medium, provided the original work is properly credited. The Creative Commons Public Domain Dedication waiver (http://creativecommons.org/publicdomain/zero/1.0/) applies to the data made available in this article, unless otherwise stated. 
and Triatoma gerstaeckeri are considered the most important vectors in the southeastern and southcentral US, respectively [5-7]. Many animals can be infected by and serve as reservoirs for T. cruzi. At least twenty-four species are recognized as natural sylvatic hosts for T. cruzi in the US including woodrats, opossums, raccoons, armadillos, and skunks $[1,8]$. T. cruzi transmission in the US was previously thought to be associated only with sylvatic or rural environments. However, Beard et al. [9] reported a domestic transmission cycle in southern Texas in which six dogs tested positive for $T$. cruzi infection and three died of Chagas disease. These findings suggest that the typically sylvatic $T$. gerstaeckeri may have passed the parasite from a sylvatic, enzootic cycle to a peridomestic cycle in dogs, which in this case may play an important role in supporting peridomestic transmission of T. cruzi [9] and increased risk of exposure for humans. In contrast to the findings in southern Texas, a recent study of factors associated with peridomestic $T$. sanguisuga demonstrated the lack of association between dog ownership and the presence of T. sanguisuga in and around houses [10]. Although the full epidemiologic role of dogs has not been well established in the US, they could play an important role in peridomestic and domestic transmission of T. cruzi as has been reported in Latin American countries [11].

Since the first autochthonous human case of Chagas disease was described in 1955, only 22 human cases have been reported that presumably were acquired via local vector-borne transmission in the US $[1,12,13]$. One of these cases was a woman from rural New Orleans, Louisiana, who was infected through the only local vector, T. sanguisuga. More than half (56\%) of twenty dead adult triatomines collected inside and around the woman's house were positive for T. cruzi by PCR analysis [14]. A more extensive study of $298 \mathrm{~T}$. sanguisuga specimens showed 180 (60.4\%) were positive for T. cruzi by PCR [15]. This prevalence was similar to that reported in $T$. gerstaeckeri collected in Texas during the years 20052006 [16].

Due to its high genetic variability, T. cruzi has been classified into six discrete typing units (DTUs) named TcI-TcVI, and a possible seventh one named Tcbat. Each DTU has been associated with different transmission cycles, hosts, and geographical distributions throughout the Americas [17]. Recent reports concerning the genetic characterization of T. cruzi stocks from the US have only demonstrated the presence of TcI (primarily in opossums and T. sanguisuga) and TcIV (primarily in raccoons, domestic dogs, and other mammals and in Triatoma species). Both DTUs have been described in domestic and wild transmission cycles [4,18]. Recent studies in Mexico report the presence of five of the six DTUs from a sample of more than 300 triatomine specimens including $T$. dimidiata, Meccus pallidipennis, $M$. longipennis and T. barberi. The samples were collected in domestic and peridomestic areas in a $T$. cruzi hyperendemic area in Veracruz and in another area in Michoacan de Ocampo $[19,20]$. These observations in areas where only TcI had been reported previously suggest that there may be a much greater diversity of T. cruzi DTUs not only in Mexico, but also in other parts of North America. Given these findings, we conducted a study to identify the diversity of circulating T. cruzi DTUs in captured rodents and $T$. sanguisuga from in and around the home of the autochthonous Chagas disease case previously reported in rural New Orleans, Louisiana.

\section{Methods}

\section{Rodent and vector collection area}

The collection area for both rodent and T. sanguisuga samples was the interior and immediate surrounding ecotopes of the residence of the first autochthonous human case of Chagas disease reported from New Orleans in 2006 [14] located on the West Bank of Orleans Parish, Louisiana [10]. The residence was situated within a zone where previously, a high prevalence of $T$. cruzi (60.4\%) was observed in T. sanguisuga [15]. Tomahawk and H. B. Sherman live-animal traps were placed for targeted trapping of rodents based on homeowner complaint and evidence of rodent activity. The domestic and peridomestic areas were allowed to be naturally recolonized by rodents until the homeowner requested that trapping resume. Trapping was conducted in four rounds beginning in September 2009, June 2011, May 2012, and February 2013. To obtain information on the organ distribution of the different $T$. cruzi strains to be identified, samples of liver, spleen, heart, and skeletal muscle were collected at necropsy and stored at $-20^{\circ} \mathrm{C}$ until testing. T. sanguisuga were collected from woodpiles surrounding the home. Teams of trained individuals methodically deconstructed each woodpile while searching for adult and immature stages of $T$. sanguisuga.

\section{Isolation and identification of $T$. cruzi from vectors}

The intestinal contents from $T$. sanguisuga collected during 2012-2013 were analyzed by direct microscopic observation to identify flagellate organisms resembling T. cruzi. Feces from vectors with positive observation for flagellates were cultured in NNN (Novy, McNeal and Nicolle) medium supplemented with RPMI1640 (Roswell Park Memorial Institute), $20 \%$ fetal bovine serum and $80 \mathrm{mg} / \mathrm{ul}$ gentamicin at $28^{\circ} \mathrm{C}$. Cultures were checked every third day until T. cruzi parasites were detected.

\section{Diagnosis of $T$. cruzi infection}

DNA was extracted from samples, including heart, liver, spleen and skeletal muscle obtained from each rodent, feces from insects, and isolated parasites from $T$. 
sanguisuga feces maintained in culture using DNeasy Blood \& Tissue Kit (QIAGEN, Valencia, CA). All DNA samples were tested by PCR for the presence of T. cruzi. DNA from four different reference strains of $T$. cruzi maintained in our laboratory was also extracted for use as positive controls. The reference strains were chosen to correspond to four different DTUs: Sylvio X10 (DTU TcI), Esmeraldo (DTU TcII), CAN III (DTU TcIV) and SC43 cl1 (DTU TcV). In addition, DNA was extracted from tissues of two un-infected mice from Tulane University's Department of Comparative Medicine. A no DNA template negative control was also used in the PCR.

Diagnostic PCR was performed on all samples using two different molecular markers for T. cruzi: the minicircle variable region of the kinetoplastid DNA (kDNA) using the primers S35/S36 and the highly repetitive genomic satellite DNA (satDNA) using the primers TcZ1/ TcZ2 (Table 1).

Amplification was performed in a final volume of $25 \mu \mathrm{L}$. To increase the Taq polymerase performance a mixture of $18 \mu \mathrm{L}$ of Apex ${ }^{\text {ma }}$ Hot start 1.0X PCR Master Mix (Genesee Scientific, USA) was used with $1.5 \mu \mathrm{M}$ of each primer set (S35/S36 or TcZ1/TcZ2) and $20 \mathrm{ng}$ of template DNA. For kDNA amplification, products were generated in a C1000 Touch $^{\text {Tw }}$ Thermal Cycler (Bio-Rad, USA), and the cycling conditions were as follows: an initial denaturation step at $95^{\circ} \mathrm{C}$ for $5 \mathrm{~min}$, followed by 30 amplification cycles of $95^{\circ} \mathrm{C}$ for 1 minute, $60^{\circ} \mathrm{C}$ for $1 \mathrm{~min}$, and $72^{\circ} \mathrm{C}$ for $1 \mathrm{~min}$ with a final extension step at $72^{\circ} \mathrm{C}$ for $5 \mathrm{~min}$ [26]. Cycling conditions for satDNA were as follows: an initial denaturation step at $94^{\circ} \mathrm{C}$ for $5 \mathrm{mi}-$ nutes was followed by 40 cycles of $94^{\circ} \mathrm{C}$ for 45 seconds, $68^{\circ} \mathrm{C}$ for 1 minute, $72^{\circ} \mathrm{C}$ for 1 minute and a final extension step at $72^{\circ} \mathrm{C}$ for ten minutes [27]. PCR products were separated on $2 \%$ agarose gels and visualized with ethidium bromide. Those samples demonstrating banding at $330 \mathrm{bp}$ for $\mathrm{kDNA}$ and/or $188 \mathrm{bp}$ for satDNA were considered $T$. cruzi-positive and selected for further genotyping.

\section{Molecular identification of $T$. cruzi DTUs}

T. cruzi genotyping was accomplished using three different molecular markers. The first marker tested was the intergenic region of the miniexon gene of T. cruzi. This was analyzed by multiplex PCR using five primers: Tc1 (DTU TcI), Tc2 (DTUs TcII-V-VI), Tc3 (DTUs TcIII-IV), $\operatorname{Tr}$ (T. rangeli), and Me (common oligonucleotide downstream from the most conserved part of the miniexon gene) (Table 1). PCR was performed in a $25 \mu \mathrm{L}$ reaction mixture, containing Apex ${ }^{\mathrm{mm}}$ Hot start 1.0X PCR Master Mix (Genesee Scientific, USA), $1.5 \mu \mathrm{M}$ of each primer and $40 \mathrm{ng}$ of DNA extracted from tissue samples or 20 ng of DNA extracted from triatomine feces or parasites from culture media. Amplification products were generated in a C1000 Touch $^{\text {Tw }}$ Thermal Cycler (Bio-Rad, USA) using 35 cycles of $5 \mathrm{~min}$ at $94^{\circ} \mathrm{C}, 30$ seconds at $94^{\circ}$ C, 30 seconds at $55^{\circ} \mathrm{C}$, and 30 seconds at $72^{\circ} \mathrm{C}$ followed by a final extension step at $72^{\circ} \mathrm{C}$ for 7 minutes. This technique distinguishes TcI from other DTUs and groups the remaining DTUs into two groups based on the size of the amplified product. In this reaction, TcI has an expected fragment of $200 \mathrm{bp}$; TcII, TcV, and TcVI have an expected fragment of $250 \mathrm{bp}$; and TcIII and TcIV have an expected fragment of $150 \mathrm{bp}$. Samples determined to be TcII, TcV, or TcVI were further classified by PCR amplification of the D7 divergent domain of the $24 S \alpha$ rRNA gene and the size-variable domain of the 18S rRNA gene. The primers used were D71/D72 and V1/V2, respectively (Table 1 ).

Table 1 Primers used for the detection and genotyping of Trypanosoma cruzi. Primer

\begin{tabular}{llll}
\hline & Sequence & Target & Reference \\
\hline S35 & 5'-AAA TAA TGT ACG GGK GAG ATG CAT GA & Minicircle variable region of kDNA \\
S36 & 5'-GGG TTC GAT TGG GGT TGG TGT & Nuclear satellite DNA \\
TCZ1 & 5'-CGA GCT CTT GCC CAC ACG GGT GCT & \\
TCZ2 & 5'CCT CCA AGC AGC GGA TAG TTC AGG & Miniexon intergenic region \\
TC1 & 5'-ACA CTT TCT GTG GCG CTG ATC G & \\
TC2 & 5'-TTG CTC GCA CAC TCG GCT GCA T & \\
TC3 & 5'-CCG CGW ACA ACC CCT MAT AAA AAT G & \\
Tr & 5'-CCT ATT GTG ATC CCC ATC TTC G & \\
Me & 5'-TAC CAA TAT AGT ACA GAA ACT G & D7 divergent domain of the 24Sa rRNA gene \\
D71 & 5'-AAG GTG CGT CGA CAG TGT GG & Size-variable domain of the 18S rRNA gene \\
D72 & 5'-TT TCA GAA TGG CCG AAC AGT & \\
V1 & 5'-CAA GCG GCT GGG TGG TTA TTC CA & [23] \\
V2 & 5'-TTG AGG GAA GGC ATG ACA CAT GT & [25]
\end{tabular}




\section{Sequencing and editing of the miniexon gene intergenic region}

DTU identification was confirmed by sequencing PCR amplicons from the miniexon intergenic region after purification using a PureLinkTM Quick PCR purification kit (Invitrogen ${ }^{\oplus}$ ). For samples that showed more than one amplification band for a molecular marker, each band was excised and recovered using ZymocleanTM Gel DNA Recovery Kit (Genesee Scientific ${ }^{\oplus}$ ) according to the manufacturer's instructions. All samples were sequenced by GENEWIZ, Inc (South Plainfield, NJ) using Applied Biosystems' BigDye version 3.1 and Applied Biosystems' 3730xl DNA Analyzer. The sequences were edited manually using MEGA version 5 software [28]. A total of 15 sequences of sufficient quality were obtained for analysis (S26MS NOLA, S18MH NOLA, S26ML NOLA, S38MH2 NOLA, S14MH NOLA, S52RH2 NOLA, S38MH1 NOLA, S52RH1 NOLA, S6MM NOLA, S6ML NOLA, S7MH NOLA, S9MS NOLA, S29MH NOLA, S29ML NOLA, and S26MHNOLA (Accession numbers: KM376435- KM376449)).

\section{Phylogenetic analysis}

Maximum-likelihood (ML) method was performed for the phylogenetic analysis [28,29]. A total of 27 sequences were used, including 15 sequences corresponding to T. cruzi from the collected rodent tissue samples and 12 reference sequences of the DTUs TcI, TcII, TcIV, TcV, TcVI. The reference sequences were obtained from the GenBank database: USAOPOSSUMcl2 (Accession number: JQ581510.1), 92090802Pcl1 (JQ581481.1), USAARMAcl3 (JQ581509.1), Gal61C (EU626731.1), Tu18 (AY367125.1), AF1Cl7 (FJ463161.1), CANIII (AY367123.1), MN (AY367128.1), VSC (FJ463159.1), SN6C (AM259471.1), Tc167(AM259480.1). The alignment was adjusted to obtain the best-fitting model based on the Akaike Information Criterion (AIC) [28]. The best fit substitution model selected for this data set was determined to be GTR (general time-reversible model) + I (invariable sites proportion) + G (a gamma disturbed rate of variation among sites). The trees and the robustness of the nodes were evaluated by bootstrap on 1000 replications by heuristic search. Trees were obtained automatically by applying Neighbor-Join and BioNJ algorithms and then selecting the topology with superior log likelihood value using MEGA version 5 software [28].

\section{Ethical approval}

All animal procedures were approved by the Tulane Institutional Animal Care and Use Committee (Protocol No. 4130).

\section{Results}

Identification and isolation of $T$. cruzi from vectors

Between 2012 and 2013, twelve specimens of triatomines were collected from peridomestic woodpiles. Species was determined using morphologic characteristics [30]. All were identified as $T$. sanguisuga and both adult and nymph insect stages were kept alive until feces could be collected for microscopic examination.

Of the twelve collected specimens, eight were positive for flagellated parasites by direct microscopic observation and six strains were successfully isolated in culture media. All six strains were confirmed as T. cruzi by diagnostic PCR. The genotyping analysis showed that all six strains belong to the TcI DTU (Figure 1).

\section{Genotyping of $T$. cruzi from rodent tissue samples}

A total of fifty-nine wild and peridomestic rodents were captured, specifically 44 mice and 15 rats. Using morphological characteristics [31], three species were identified: Peromyscus gossypinus 40/59 (67.8\%), Mus musculus 4/59 ( 6.8\%), Neotoma floridana 15/59 (25.4\%).

Using two different molecular markers, the minicircle variable region of the kinetoplastid DNA (kDNA) and the highly repetitive genomic satellite DNA (satDNA), a

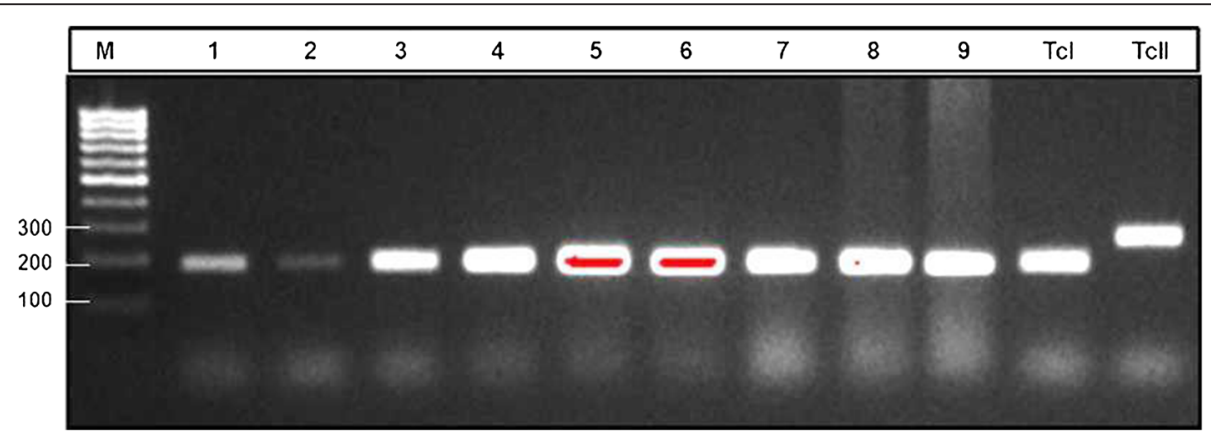

Figure 1 Molecular characterization of the flagellate forms from $T$. sanguisuga feces and $T$. cruzi strain isolates by amplification of the mini-exon intergenic region. (1-3) DNA from flagellate forms in feces: WB1F, WB2F, WB3F (4-6) DNA from T. cruzi strain isolates from feces of samples 1-3 respectively, (7-9) DNA from T. cruzi strain isolates WB4, WB758, WB759. DNA from references strains: Tcl (Sylvio 10X), Tcll (Esmeraldo). Agarose $2.5 \%$ gel. 
total of 34/44 (77.2\%) mice (32 P. gossypinus and two $M$. musculus) and 11/15 (73.3\%) rats (N. floridana) were positive for $T$. cruzi, corresponding to an overall rodent infection rate of $76 \%$ (Table 2). The genotype of T. cruzi was determined from tissue samples for positive rodents using the miniexon gene. From a total of 45 positive rodents, differentiation among DTUs was achieved in 23 rodents: 20 mice (44.4\%) and 3 rats (6.6\%). A total of 18 of these rodents $(78.2 \%)$ were found to be infected only with TcI. Single infections with non-TcI genotypes were detected in 2/23 (9\%) rodents. Mixed infections with different genotypes were detected in $3 / 23$ (13\%) rodents. These samples were further analyzed by ribosomal markers and sequencing to specify the infecting non-TcI DTU. Surprisingly, within these samples TcII was identified in two mice displaying single infection (9\%). It was also detected in $2 / 23$ (9\%) of mice in association with TcI and $1 / 23$ (4\%) of those with TcIV. Considering the data together, a total of $19 / 23(82 \%)$ rodents were infected with TcI, 5/23 (22\%) with TcII, and 2/23 (9\%) with TcIV (Table 3).

\section{Mini-exon intergenic region sequencing and phylogenetic analysis}

DTU identification was confirmed by sequencing of the mini-exon intergenic region and phylogenetic analysis on a total of 15 sequences. The analysis involved 27 nucleotide sequences with a length of $222 \mathrm{bp}$. All sequence positions containing gaps and missing data were eliminated. There were a total of 199 positions in the final dataset used to build the phylogenetic tree. The sequences were deposited in the GenBank database of the National Center for Biotechnology Information (NCBI) (http://www.ncbi.nlm.nih.gov/genbank/) (Accession numbers: KM376435- KM376449).

We analyzed the phylogenetic relationships among 27 T. cruzi DNA sequences corresponding to 15 New Orleans (NOLA) sequences from the collected rodents and 12 reference sequences from known DTUs. Significant bootstrap values were obtained with ML analysis (more than 60\%). The unrooted tree with the highest log likelihood value $(-\operatorname{lnL}=890.6637)$ allowed the identification of three main clusters for the rodent tissue samples. The first cluster of six sequences was closely related with the DTU TcII. These sequences showed high genetic

Table 2 Trypanosoma cruzi infection in rodents identified by species

\begin{tabular}{lll}
\hline Host & Species & Infection rate \\
\hline Mouse $(\mathrm{n}=44)$ & Peromyscus gossypinus & $32(73 \%)$ \\
& Mus musculus & $2(5 \%)$ \\
Rat $(\mathrm{n}=15)$ & Neotoma floridana & $11(73 \%)$ \\
Total $(\mathbf{N}=\mathbf{5 9})$ & & $\mathbf{4 5 / 5 9 ( 7 6 \% )}$ \\
\hline
\end{tabular}

Table 3 Frequency of $T$. cruzi DTUs and mixed infections in infected rodent samples successfully genotyped

\begin{tabular}{lllll}
\hline Host & \multicolumn{4}{l}{ DTU and Mixed infection frequency } \\
\cline { 2 - 5 } & Tcl only & Tcll only & Tcl-Tcll & Tcll-TcIV \\
\hline Mouse $(\mathrm{n}=20)$ & $16(80 \%)$ & $2(10 \%)$ & $1(5 \%)$ & $1(5 \%)$ \\
Rat $(\mathrm{n}=3)$ & $2(67 \%)$ & ND & ND & $1(33 \%)$ \\
Total $(\mathbf{N}=\mathbf{2 3})$ & $\mathbf{1 8 ( 7 8 \% )}$ & $\mathbf{2 ( 9 \% )}$ & $\mathbf{1 ( 4 \% )}$ & $\mathbf{2 ( 9 \% )}$ \\
\hline
\end{tabular}

ND: Not detected.

identity with the reference sequences, Tul18 and AF1Cl7, with a significant bootstrap of $92 \%$. A second cluster of two sequences corresponded to TcIV and had high genetic identity with the reference sequence CANIII with a bootstrap of $100 \%$. Finally, the cluster of seven samples corresponding to TcI was found to be closely related to TcI sequences from the US with a bootstrap of $100 \%$ and slightly less related to Colombian TcI sequences with a bootstrap of $83 \%$. None of the analyzed sequences were grouped with DTUs TcV or TcVI. These data showed a possible extensive diversity of $T$. cruzi DTUs circulating in this endemic area (Figure 2).

\section{Tissue tropism and DTUs}

Table 4 shows the number of the T. cruzi DTUs observed in the successfully genotyped rodent tissue samples. Both mice and rats had a higher proportion of parasites in the heart (91\%), followed by the liver (26\%), skeletal muscle (13\%) and spleen (13\%). Additionally, each tissue obtained from each rodent was analyzed in order to find a possible association or tropism of the DTU with a specific tissue. Although the majority of the DTUs were found predominantly in the heart, the sample numbers were not sufficient to demonstrate a significant DTU tissue association. We found single infections of the DTUs TcI and TcII in all tissues genotyped in both mice and rats. The highest frequency of T. cruzi infection observed in mice was TcI found primarily in the heart (90\%) followed by liver and skeletal muscle. Similarly, in rats the highest frequency of $T$. cruzi infection was TcI in the heart (67\%); single TcII infection was not found in rats. Mixed infections with TcII and TcIV were only found in the heart of mice and rats while single infections were observed in the other tissues. Contrary to what was expected, in these samples we did not find mixed infection with the DTUs TcI and TcIV (Table 4).

\section{Discussion}

Despite being home to one of the few US areas with an autochthonous case of human Chagas disease, there exist few studies exploring the genetic variability of $T$. cruzi parasite populations from both insect vectors and mammalian hosts in southeastern Louisiana. In the current study, the molecular analysis from $T$. sanguisuga 


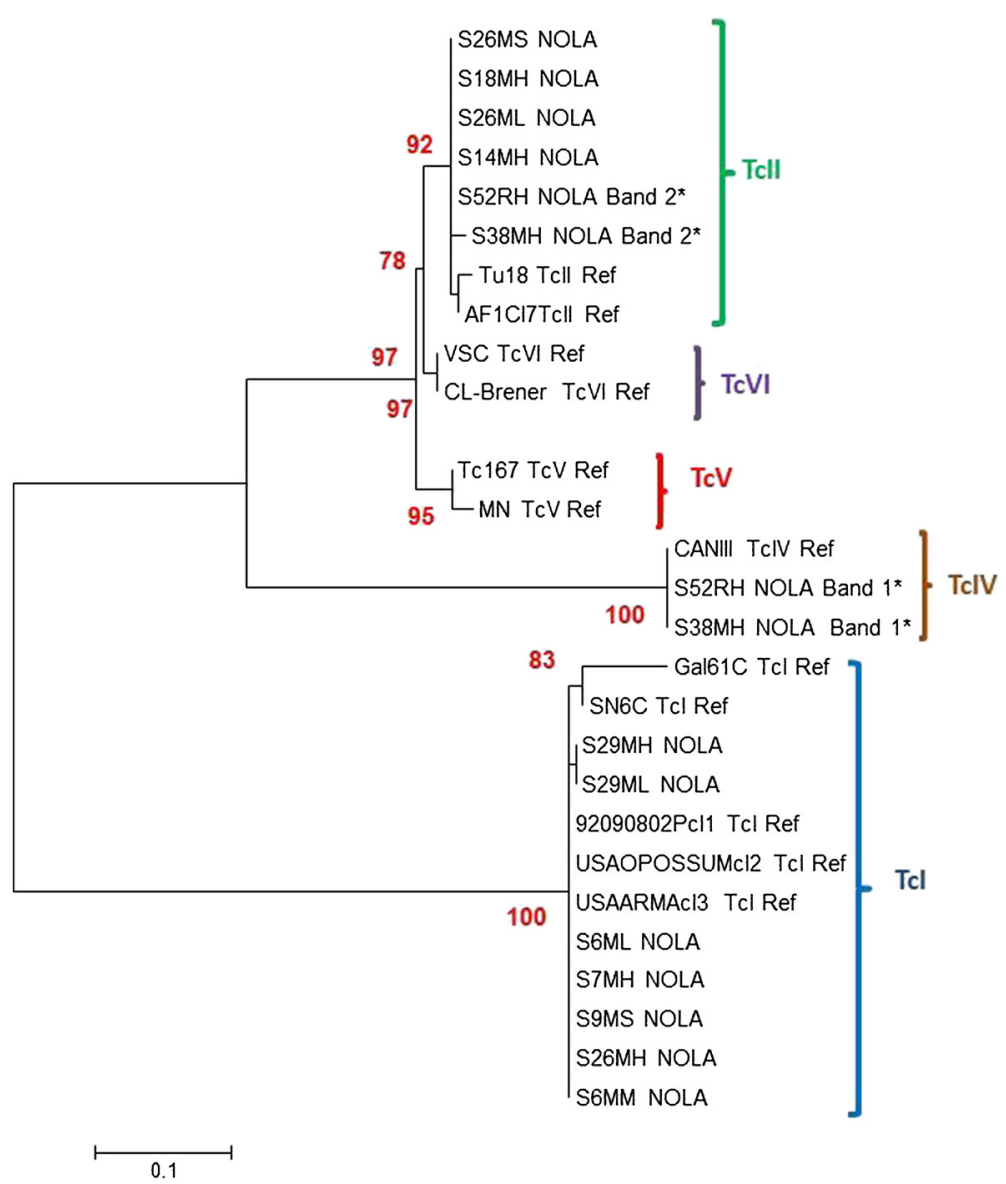

Figure 2 Molecular phylogenetic analysis by Maximum Likelihood method. The phylogram depicting the phylogenetic relationships among the 27 T. cruzi DNA sequences corresponding to eight rodents, based on Miniexon intergenic gene sequencing. The un-rooted tree with the highest $-\mathrm{InL}=890.6637$ is shown, allowing identification of the three different clusters corresponding to three different DTUs in the rodent tissue samples analyzed. Bootstrap values appear on each clustering branch. The last letter in the sample name refers to H: heart, M: skeletal muscle, L: liver, S: spleen. *indicates mice with mixed infections.

Table 4 Number of the $T$. cruzi DTUs observed in the rodent tissue samples successfully genotyped

\begin{tabular}{|c|c|c|c|c|c|}
\hline Host & DTU & Tissue & & & \\
\hline & & Heart & Liver & Skeletal muscle & Spleen \\
\hline & I Only $(n=16)$ & 14 (88\%) & $5(31 \%)$ & $2(13 \%)$ & $2(13 \%)$ \\
\hline \multirow[t]{4}{*}{ Mouse $(n=20)$} & II Only (n=2) & $2(100 \%)$ & ND & ND & ND \\
\hline & $|-| \mid+(n=1)$ & $1+(100 \%)$ & $1+(100 \%)$ & $1+(100 \%)$ & $1+(100 \%)$ \\
\hline & $\|-\operatorname{IV}(n=1)$ & $1(100 \%)$ & ND & ND & ND \\
\hline & Total* & $18 / 20(90 \%)$ & $6 / 20(30 \%)$ & $3 / 20$ (15\%) & $3 / 20(15 \%)$ \\
\hline \multirow[t]{3}{*}{ Rat $(n=3)$} & I Only & $2(67 \%)$ & ND & ND & ND \\
\hline & IIIV & 1 (33\%) & ND & ND & ND \\
\hline & Total** & $3 / 3(100 \%)$ & $0 / 3(0 \%)$ & $0 / 3(0 \%)$ & $0 / 3(0 \%)$ \\
\hline Total $(\mathrm{N}=23)^{* * * *}$ & & $21 / 23(91 \%)$ & $6 / 23(26 \%)$ & $3 / 23(13 \%)$ & $3 / 23(13 \%)$ \\
\hline
\end{tabular}

ND: Not detected.

† DTU TCl was found in the heart and TCll was found in the other tissues in the same mouse.

*Total of mice.

**Total of rats.

***Total of rodents. 
feces showed a high prevalence $(66 \%)$ of $T$. cruzi in this vector. This corroborates the prevalence from the same endemic area previously reported by Cesa et al. [15]. Genotyping of the strains isolated from the vectors confirmed the presence of $\mathrm{TcI}$ in these samples. Because only twelve $T$. sanguisuga specimens were analyzed, it will be necessary to expand the number of triatomine samples to better evaluate the presence of the other DTUs.

Although rodents have been reported as common hosts for T. cruzi, few of these studies have been done in the US. The analysis of different species of small rodents in southern Texas showed a high serological prevalence of $T$. cruzi in the species tested [3]. In our study we report an even higher PCR prevalence of T. cruzi in tissues of small rodents with an infection rate of $76 \%$, compared with the infection found in southern Texas plains wood rats $(34 \%)$, larger mammals such as raccoons (63\%), and Virginia opossums (33\%) [3,32]. It is unclear why rodents in our study have such a high prevalence of $T$. cruzi infection. It is possible that rodents are more susceptible to T. cruzi infection, or that they maintain much higher parasitemias because of their insectivore behavior. It is also unclear what the importance of this high prevalence is from an epidemiological perspective, especially as it relates to the risk for human infection.

Although the first genotyping reports from the US showed the presence of only TcI and TcIV $[1,33]$, our genotyping and phylogenetic analysis indicate the presence of at least three different DTUs (TcI, TcII and TcIV) present in rodents in a small area in rural New Orleans, Louisiana. These results are consistent with the recent findings in southern Mexico where five different DTU's (TcI, TcII, TcIII, TcIV and TcV) were found in local triatomine collections [19]. Considering that until a few years ago only TcI had been reported in southern Mexico, it is interesting that both $\mathrm{TcI}$ and $\mathrm{TcV}$ are now being found at the same frequency (27\%) in triatomine vectors in this region. These findings do not necessarily represent a change in DTU distribution, but may just be the result of improvements in $T$. cruzi genotyping methods. In addition, in our study we used direct genotyping from biological samples, since culturing parasites prior to genotyping might induce potential bias due to loss of strains or culture selection. In the New Orleans samples, we found a majority contained TcI (82\%), which corroborates previous analyses indicating that TcI is the most frequent DTU in raccoons and opossums in the United States [18,33]. Nonetheless, the relatively high frequency of other DTUs found: TcII (22\%) and TcIV (9\%) indicates the presence of a greater genetic diversity of $T$. cruzi strains in small rodents. In addition, the high $T$. cruzi infection rate we detected suggests the potential for a biological or ecological implication of these small rodents in the peridomestic enzootic cycle of T. cruzi. Given the proximity of the collected rodents to humans, further studies should extend collections and analysis to similar rodent populations to assess their epidemiologic importance in autochthonous transmission of T. cruzi.

The phylogenetic analysis of the miniexon gene of the NOLA T. cruzi sequences showed a strong cluster association with reference sequences of DTU TcII corresponding to Tul18 and AFcl17, with a significant bootstrap value of $92 \%$ obtained with ML. A previous phylogenetic analysis of the $24 \mathrm{~S} \alpha$ subunit gene found $T$. cruzi isolates from Triatoma protracta in California that were grouped in a clade with some TcII and TcVI reference strains, but the different DTUs were not resolved [34]. Our analysis showed a strong and well defined association with the TcII in small rodents, indicating a higher genetic diversity of $T$. cruzi in the US.

It has been shown that different DTUs of T. cruzi can be found circulating in the same individual but there is limited evidence that different DTUs can be found in different tissue types within the same host [35-37]. Although DTUs have not shown a strict tropism, a clear association with different types of tissues has been identified [38-40]. In our study the tissue analysis from naturally infected rodents did not show a specific tissue tropism, but they did display mixed infections with DTUs TcI-TcII (different tissues in the same host), and TcII-TcIV (co-infecting tissues in the same hosts). This suggests that there may be a dominance of one of these two DTUs in a tissue-dependent manner.

Epidemiologic evidence suggests a preferential association of T. cruzi DTUs TcI and TcII with marsupials and placental mammals, respectively. While TcI was initially associated with marsupials and sylvatic triatomines in wild environments, several studies have shown its presence in domestic environments and linked it with human infections and oral transmission [29,41-43]. TcII is epidemiologically associated with primates, and it is usually found in human infections in the Southern cone countries of South America [44-47]. The presence of TcI, TcII, and TcIV in small rodents in New Orleans may indicate an important role of these mammals in the eco-epidemiological cycle of $T$. cruzi in this region.

This hypothesis will require validation by the examination of additional samples and parasite isolates from the region to better understand the underlying enzootic cycle of T. cruzi and how this cycle interfaces with the human population. Identification of TcII in this area for the first time shows that more than TcI and TcIV are present in small mammals in wild and peridomestic locations. Further analysis is necessary to improve the understanding of the molecular epidemiology of T. cruzi DTUs circulating in the region. 


\section{Conclusions}

Though the number of samples is limited, our results indicate a greater diversity than previously reported in the T. cruzi DTUs circulating among triatomine vectors and rodents captured near the house of an autochthonous human Chagas disease case in rural New Orleans. This work should stimulate similar studies in other areas of North America to better understand T. cruzi transmission dynamics in sylvatic and domestic cycles among mammals and insect vectors, since such knowledge is crucial to evaluate the transmission risk of $T$. cruzi to humans and their associated domestic animals in the US.

\section{Competing interests}

The authors declare that they have no competing interests.

\section{Authors' contributions}

$\mathrm{CH}$ and DW conceived and designed the study. $\mathrm{CH}, \mathrm{ML}$, and $\mathrm{CN}$ carried out the experiments. SJ carried out field work and sample collection and wrote the field methodology. $\mathrm{CH}$ and $\mathrm{ML}$ analyzed the data. $\mathrm{CH}$ and DW wrote the paper. All authors read and approved the final manuscript.

\section{Acknowledgments}

The authors would like to thank Dr. Pierre Buekens for supporting this study. This work was funded in part by a Research Enhancement grant from Tulane University to DW. We also thank Dr. Yves Carlier and Dr. Eric Dumonteil for critical revisions of the manuscript.

\section{Received: 15 October 2014 Accepted: 12 February 2015}

\section{Published online: 24 February 2015}

\section{References}

1. Bern C, Kjos S, Yabsley MJ, Montgomery SP. Trypanosoma cruzi and Chagas' Disease in the United States. Clin Microbiol Rev. 2011;24(4):655-81.

2. Gascon J, Bern C, Pinazo MJ. Chagas disease in Spain, the United States and other non-endemic countries. Acta Trop. 2010;115:22-7.

3. Charles RA, Kjos S, Ellis AE, Barnes JC, Yabsley MJ. Southern plains woodrats (Neotoma micropus) from southern Texas are important reservoirs of two genotypes of Trypanosoma cruzi and host of a putative novel Trypanosoma species. Vector Borne Zoonotic Dis. 2013;13(1):22-30.

4. Roellig DM, Savage MY, Fujita AW, Barnabe C, Tibayrenc M, Steurer FJ, et al. Genetic variation and exchange in Trypanosoma cruzi isolates from the United States. PLoS One. 2013;8(2):e56198.

5. Kjos SA, Marcet PL, Yabsley MJ, Kitron U, Snowden KF, Logan KS, et al. Identification of bloodmeal sources and Trypanosoma cruzi infection in triatomine bugs (Hemiptera: Reduviidae) from residential settings in Texas, the United States. J Med Entomol. 2013;50(5):1126-39.

6. Schofield CJ, Galvao C. Classification, evolution, and species groups within the Triatominae. Acta Trop. 2009;110(2-3):88-100.

7. Kribs-Zaleta C. Estimating contact process saturation in sylvatic transmission of Trypanosoma cruzi in the United States. PLoS Negl Trop Dis. 2010;4(4):e656.

8. Montgomery SP, Starr MC, Cantey PT, Edwards MS, Meymandi SK. Neglected parasitic infections in the United States: Chagas disease. Am J Trop Med Hyg. 2014;90(5):814-8.

9. Beard CB, Pye G, Steurer FJ, Rodriguez R, Campman R, Peterson AT, et al. Chagas disease in a domestic transmission cycle, southern Texas. USA Emerg Infect Dis. 2003;9(1):103-5.

10. Moudy RM, Michaels S, Jameson SB, Londono B, Lopez V, Caillouet KA, et al. Factors associated with peridomestic Triatoma sanguisuga (Hemiptera: Reduviidae) presence in southeastern Louisiana. J Med Entomol. 2014;51:1043-50

11. Gurtler RE, Cecere MC, Vazquez-Prokopec GM, Ceballos LA, Gurevitz JM, Fernandez Mdel P, et al. Domestic animal hosts strongly influence humanfeeding rates of the Chagas disease vector Triatoma infestans in Argentina. PLoS Negl Trop Dis. 2014;8(5):e2894.

12. Woody N, Woody H. American trypanosomiasis (Chagas' disease). First indigenous case in the United States. JAMA. 1955;159:676-7.
13. Cantey PT, Stramer SL, Townsend RL, Kamel H, Ofafa K, Todd CW, et al. The United States Trypanosoma cruzi infection study: evidence for vector-borne transmission of the parasite that causes Chagas disease among United States blood donors. Transfusion. 2012;52:1922-30.

14. Dorn PL, Perniciaro L, Yabsley MJ, Roellig DM, Balsamo G, Diaz J, et al. Autochthonous transmission of Trypanosoma cruzi, Louisiana. Emerg Infect Dis. 2007;13(4):605-7.

15. Cesa K, Caillouet KA, Dorn PL, Wesson DM. High Trypanosoma cruzi (Kinetoplastida: Trypanosomatidae) Prevalence in Triatoma sanguisuga (Hemiptera: Redviidae) in southeastern Louisiana. J Med Entomol. 2011;48(5):1091-4.

16. Kjos SA, Snowden KF, Olson JK. Biogeography and Trypanosoma cruzi infection prevalence of Chagas disease vectors in Texas, USA. Vector Borne Zoonotic Dis. 2009;9(1):41-50.

17. Zingales B, Miles MA, Campbell DA, Tibayrenc M, Macedo AM, Teixeira MMG, et al. The revised Trypanosoma cruzi subspecific nomenclature: rationale, epidemiological relevance and research applications. Infect Genet Evol. 2012;12:240-53.

18. Barnabe C, Yaeger R, Pung O, Tibayrenc M. Trypanosoma cruzi: A considerable phylogenetic divergence indicates that the agent of Chagas disease is indigenous to the native fauna of the United States. Exp Parasitol. 2001;99:73-9.

19. Ramos-Ligonio A, Torres-Montero J, Lopez-Monteon A, Dumonteil E. Extensive diversity of Trypanosoma cruzi discrete typing units circulating in Triatoma dimidiata from central Veracruz, Mexico. Infect Genet Evol. 2012;12(7):1341-3.

20. Ibanez-Cervantes G, Martinez-Ibarra A, Nogueda-Torres B, Lopez-Orduna E, Alonso AL, Perea C, et al. Identification by Q-PCR of Trypanosoma cruzi lineage and determination of blood meal sources in triatomine gut samples in Mexico. Parasitol Int. 2013;62(1):36-43.

21. Sturm NR, Degrave W, Morel C, Simpson L. Sensitive detection and schizodeme classification of Trypanosoma cruzi cells by amplification of kinetoplast minicircle DNA sequences: use in diagnosis of Chagas' disease. Mol Biochem Parasitol. 1989;33(3):205-14.

22. Moser DR, Kirchhoff LV, Donelson JE. Detection of Trypanosoma cruzi by DNA amplification using the polymerase chain reaction. J Clin Microbiol. 1989;27(7):1477-82.

23. Fernandes O, Santos SS, Cupolillo E, Mendonca B, Derre R, Junqueira AC, et al. A mini-exon multiplex polymerase chain reaction to distinguish the major groups of Trypanosoma cruzi and T. rangeli in the Brazilian Amazon. Trans R Soc Trop Med Hyg. 2001;95(1):97-9.

24. Souto RP, Zingales B. Sensitive detection and strain classification of Trypanosoma cruzi by amplification of a ribosomal RNA sequence. Mol Biochem Parasitol. 1993;62:45-52.

25. Clark CG, Pung OJ. Host specificity of ribosomal DNA variation in sylvatic Trypanosoma cruzi from North America. Mol Biochem Parasitol. 1994;66(1):175-9.

26. Vallejo GA, Guhl F, Chiari E, Macedo AM. Species specific detection of Trypanosoma cruzi and Trypanosoma rangeli in vector and mammalian hosts by polymerase chain reaction amplification of kinetoplast minicircle DNA. Acta Trop. 1999;72:203-12.

27. Schijman AG, Bisio M, Orellana L, Sued M, Duffy T, Mejia Jaramillo AM, et al. International study to evaluate PCR methods for detection of Trypanosoma cruzi DNA in blood samples from Chagas disease patients. PLoS Negl Trop Dis. 2011:5(1):e931.

28. Tamura K, Peterson D, Peterson N, Stecher G, Nei M, Kumar S. MEGA5: molecular evolutionary genetics analysis using maximum likelihood, evolutionary distance, and maximum parsimony methods. Mol Biol Evol. 2011;28(10):2731-9.

29. Herrera C, Guhl F, Falla A, Fajardo A, Montilla M, Adolfo Vallejo G, et. al. Genetic variability and phylogenetic relationships within Trypanosoma cruzi I isolated in Colombia based on miniexon gene sequences. J Parasitol Res 2009, ID 897364, 9.

30. Lent HWP. Revision of the Triatominae (Hemiptera, Reduviidae) and their significance as vectors of Chagas' disease. Bull Amer Mus Natur Hist. 1979;163:123-520.

31. Choate JR, Jones Jr JK, Jones C. Handbook of mammals of the south-central states. Baton Rouge: Louisiana State University Press; 1994.

32. Roellig DM, Ellis AE, Yabsley MJ. Genetically different isolates of Trypanosoma cruzi elicit different infection dynamics in raccoons (Procyon lotor) and Virginia opossums (Didelphis virginiana). Int J Parasitol. 2009;39:1603-10. 
33. Roellig DM, Brown EL, Barnabe C, Tibayrenc M, Streurer FJ, Yabsley MJ. Molecular Typing of Trypanosoma cruzi Isolates, United States. Emerg Infect Dis. 2008;14(7):1123-5.

34. Hwang WS, Zhang G, Maslov D, Weirauch C. Infection rates of Triatoma protracta (Uhler) with Trypanosoma cruzi in southern California and molecular identification of trypanosomes. Am J Trop Med Hyg. 2010;83(5):1020-2

35. Llewellyn MS, Rivett-Carnac JB, Fitzpatrick S, Lewis MD, Yeo M, Gaunt MW, et al. Extraordinary Trypanosoma cruzi diversity within single mammalian reservoir hosts implies a mechanism of diversifying selection. Int J Parasitol. 2011:41:609-14.

36. Burgos JM, Begher S, Silva HM, Bisio M, Duffy T, Levin MJ, et al. Molecular identification of Trypanosoma cruzi I tropism for central nervous system in Chagas reactivation due to AIDS. Am J Trop Med Hyg. 2008;78(2):294-7.

37. Valadares HMS, Pimenta JR, Freitas JM, Duffy T, Bartholomeu DC, Oliveira RP, et al. Genetic profiling of Trypanosoma cruzi directly in infected tissues using nested PCR of polymorphic microsatellites. Int J Parasitol. 2008;38:839-50.

38. Bosseno MF, Yacsik N, Vargas F, Breniere SF. Selection of Trypanosoma cruzi clonal genotypes (Clonet 20 and 39) isolated from Bolivian triatomines following subculture in liquid medium. Mem Inst Oswaldo Cruz. 2000;95(5):601-7.

39. Solari A, Campillay R, Ortiz S, Wallace A. Identification of Trypanosoma cruzi genotypes circulating in Chilean chagasic patients. Exp Parasitol. 2001;97(4):226-33.

40. Melquiades Rodrigues C, Valadares HMS, Fortes Fancisco A, Marilda Arantes J, Franca Campos C, Teixeira-Carvahlo A, et al. Coinfection with different Trypanosoma cruzi strains interferes with the host immune response to infection. PLoS Negl Trop Dis. 2010;4(10):846

41. Jansen AM, Santos De Pinho AP, Lisboa CV, Cupolillo E, Mangia RH, Fernandes O. The sylvatic cycle of Trypanosoma cruzi: a still unsolved puzzle. Mem Inst Oswaldo Cruz. 1999;94:203-4.

42. O'Connor O, Bosseno MF, Barnabe C, Douzery EJP, Breniere SF. Genetic clustering of Trypanosoma cruzi I lineage evidenced by intergenic miniexon gene sequencing. Infect Genet Evol. 2007;7:587-93.

43. Botero A, Ortiz S, Muñoz S, Triana O, Solari A. Differentiation of Trypanosoma cruzi and Trypanosoma rangeli of Colombia using minicircle hybridization tests. Diagn Microbiol Infect Dis. 2010;68:265-70.

44. Fernandes O, Souto RP, Castro JA, Pereira JB, Fernandes NC, Junqueira AC, et al. Brazilian isolates of Trypanosoma cruzi from humans and triatomines classified into two lineages using mini-exon and ribosomal RNA sequences. Am J Trop Med Hyg. 1998;58(6):807-11.

45. Fernandes O, Santos S, Junqueira A, Jansen A, Cupolillo E, Campbell D, et al. Populational heterogeneity of Brazilian Trypanosoma cruzi isolates revealed by the mini-exon and ribosomal spacers. Mem Inst Oswaldo Cruz. 1999;94 Suppl 1:195-7.

46. Zingales B, Souto RP, Mangia RH, Lisboa CV, Campbell DA, Coura JR, et al. Molecular epidemiology of American trypanosomiasis in Brazil based on dimorphisms of rRNA and mini-exon gene sequences. Int J Parasitol. 1998;28(1):105-12

47. Fernandes $\mathrm{O}$, Mangia RH, Lisboa CV, Pinho AP, Morel CM, Zingales B, et al. The complexity of the sylvatic cycle of Trypanosoma cruzi in Rio de Janeiro state (Brazil) revealed by the non-transcribed spacer of the mini-exon gene. Parasitology. 1999;118(2):161-6.

\section{Submit your next manuscript to BioMed Central and take full advantage of:}

- Convenient online submission

- Thorough peer review

- No space constraints or color figure charges

- Immediate publication on acceptance

- Inclusion in PubMed, CAS, Scopus and Google Scholar

- Research which is freely available for redistribution 